\title{
VIRTÙ, FORTUNA E MORAL EM O PRÍNCIPE, DE NICOLAU MAQULAVEL
}

\author{
Caio Gracco Pinheiro Dias \\ Doutorando em Direito Internacional pela \\ Faculdade de Direito da Universidade de São \\ Paulo.
}

Resumo:

As opiniões sobre, Maquiavel autor de O Príncipe como as dos piagnoni, seguidores do Frei Girolano Savanarola; os reveses decorrentes das respostas dadas à pergunta. qual o motivo de ele ter escrito o livro, na época da derrubada dos Médici, em 1527, são alguns dos temas abordados pelo autor que interpreta os dois conceitos-chaves da obra, virtù e fortuna.

Abstract:

The opinions on Maquiavel, author of "The Prince" as of piagnoni, followers of the Frei Girolano Savanarola; the decurrent consequences of the answers given to the question, what is the reason of him to have written the book, at the time of the falling of the Médici. in 1527, are some of the subjects taken by the author who interprets the two main concepts of the work, virtu and richness.

Unitermos: O Príncipe; Nicolau Maquiavel; virtù; fortuna; patriotismo; projeto de unificação política.

Keywords: The Prince; Nicolau Maquiavel; virtù: fortune; patriotism; project of politics unification.

Introdução

Quem quer que escreva no alto de uma página em branco o nome de Maquiavel não pode deixar de sentir uma espécie de angústia: depois de centenas de outros escritores e soberanos, historiadores e filósofos, teóricos da politica e estrategistas, moralistas e teólogos, também ele se prepara para interrogar a esfinge, o diplomata a serviço de Florença, o patriota italiano, o autor cuja prosa, clara a cada trecho e equívoca no conjunto, dissimula as intenções, cujas contínuas intuições desafiam há quatro 
séculos a engenhosidade dos comentadores; também ele se prepara para fazer uma iscolha que sabe que já foi feita antes dele. Pois a interpretação que irá propor, qualquer que seja ela, não the pertence pessoalmente.

('om essas palavras. Raymond Aron inicia seu ensaio "Maquiavel e Marx" ' tocando num ponto sensível da literatura acerca do escritor florentino: qual exatamente teria sido o motivo de Maquiavel para escrever "O Príncipe"? Essa pergunta, chave para o entendimento da teoria política contida no livro, tem sido objeto de acalorado debate. Ainda durante sua vida, Maquiavel sofreu reveses decorrentes das respostas dadas a essa pergunta: por ocasião da derrubada dos Médici em 1527. restaurada a República Florentina, é hustilizado e demovido do cargo público que voltara a ocupar em agosto de 1525 , entre outras razões. porque:

[o]s ricos achavam que aquele seu Principe fosse um documento que ensinava ao Duque como tirar deles todas as riquezas, e os pobres julgavam $O$ Príncipe um documento destinado a ensinar ans ricos como tirar a liberdade dos pobres; os chorões ${ }^{2}$ tinham Maquiavel como herético; os bons o consideravam um desonesto; os tristes o achavam mais triste ou mais valente que eles; assim, todos o odiavam. ${ }^{3}$

1. Publicado como apêndice na tradução brasilcira d' $O$ Principe, da lavra de Maria Júlia (ioldwasser, publicada pela ed. Martins Fontes (2001). Neste trabalho, salvo quando expressamente indicado o contrário, as remissões a páginas da obra referem-se a essa edição.

2. "Chorôes" (no italiano, piagnoni) era o termo utilizado para denominar os seguidores do Frei Girolamo Savonarola (1452-1498), religioso florentino cujas idéias inspiraram o govemo de Florença depois da queda de Pietro de Médici. em 1494, quando foi implantada uma espécie de democracia teocrática. Lram assim chamados porque costumavam lamentar, em voz alta, a corrupção dos costumes da cidade, cuja "regeneração" foi o mote da atuação política de Savonarola.

3. BUSINI, Giovambattista. Lettere di Giovambattista Busini a Benedetto Varchi sopra l'assedio di Firenze. ('itado na cronologia da vida de Maquiavel contida na edição d'O Principe mencionada na nota 2 . 
A essas primeiras apaixonadas opiniões, outras vieram se somar. JeanJacques Rousseau, numa passagem e nota do Cap. VI do Livro III d'O C'ontrato Social, proclama que "[o] Principe de Maquiavel é o livro dos republicanos" pois "fingindo dar lições aos reis, ele as deu aos montes ao povo". posição que justifica da seguinte maneira:

Maquiavel era um homem honesto e um bom cidadão; porém, estando ligado à casa dos Medicis, era obrigado, em meio à opressão de sua pátria, a disfarçar seu amor pela liberdade. Só a escolha de seu execrável herói ${ }^{4}$ é suficiente para mostrar sua intenção secreta; e a oposição das máximas de seu livro sobre o principe àquelus de seus Discursos sobre Tito Livio e de sua História di Florença, demonstra que esse profundo politico só teve até aqui leitores superficiais ou corrompidos.

Outras interpretaçõcs poderiam ser citadas, mas não o faremos aqui, até porque seria impossível elencá-las todas: é provável que delas existam tantas quantas sejam as pessoas que se propuseram a escrever sobre a obra do florentino. Nossa proposta é seguir apenas uma delas, que consideramos fazer jus à importância da obra de Maquiavel. Para isso, primeiro buscamos hixar duas características do autor que são essenciais para a sua compreensão: scu profundo patriotismo e sua visão realista do mundo. A partir desses dois pontos, podemos justificar nossa interpretação de um possivel objetivo para a feitura d'O Príncipe e, isso esclarecido, interpretar os dois conceitos-chaves da obra, virtiu c fortuna.

I. Acima de tudo. um Patriota.

Uma característica marcante da personalidade de Niculau Maquiavel, ao menos a que denotam seus escritos, é a sua profunda ligação à sua pátria. Todavia, desde logo se deve esclarecer que a pátria, para Maquiavel, não cra a cidade de

4. Cesare Borgia, o Duque Valentino, cuja trajetória é relatada por Maquiavel no Cap. VII d'O Principe. 
Florença, à qual serviu por tantos anos em posições de destaque, mas a Itália, ainda que dividida numa infinidade de pequenas e belicosas unidades politicas, disputando a hegemonia na península umas com as outras. Isso fica evidente, entre outras passagens, no próprio título do capítulo de encerramento d'O Príncipe: Exorlação a tomar a Itália e libertá-la das mãos dos bárbaros. Além disso, em várias passagens. Maquiavel se refere à Itália como um país, acima das divisões políticas que resultaram após a queda do Império Romano do Ocidente. Vejam-se, a tílulo de exemplo, os seguintes trechos:

[Referindo-se aos principes italianos que utilizaram exércitos mercenários] $O$ resultado de sua virtú foi a Itália ter sido invadida por Carlos, pilhada por Luis, violentada por Fernando e vilipendiada pelos suiços. (...) Assim, levaram a Itália a ser escravizada e vilipendiada. (p. 62).

Considerando todas as coisas ditas acima e refletindo eu mesmo se o momento atual da Itália é propicio a um principe novo, isto é, se existe matéria que justifique que um principe prudente e valoroso the dê forma, trazendoIhe glória pessoal e beneficios para todos os homens do pais... ${ }^{6}$ (p. 123).

Maquiavel, assim, entende que a Itália é um todo que se projeta para além das fronteiras politicas dos pequenos Estados em que se divide. Isso fica mais claro ao se notar o uso que faz do termo província como sendo uma região com certa unidade étnica e lingüística, não necessariamente coincidente com as fronteiras políticas, sendo essa semelhança de costumes um fator facilitador da conquista c manutenção de novos Fstados, como se vê no seguinte trecho:

5. Note-se a progressiva personificação da figura da ltália. que a cada adjetivo utilizado por Maquiavel (invadida, pilhada. violentada, vilipendiada. sscravizada) mais se distancia de uma idéia política abstrata. assumindo a feição de uma mulher.

6. No original italiano, a palavra pais nâo ć utilizada, mas é estabclecida uma relação direta entre a Itália e "os homens dela" (uomini di quella), que claramente mostra que. na concepção do autor. para além da ligação dos italianos com os reinos sob o domínio dos quais viviam. eles estavam ligados à pátria Italiana, sem "forma", i.e.. politicamente dividida, mas ainda assim existente. 
Afirmo, portanto, que os estados que, depois de conquistados, são anexados a um antigo estado de quemo conquistou ou são da mesma provincia e lingua deste ou não o são. Se forem, será fácil conservá-los, principalmente se não estiverem habituados a viver livres. Para possui-los com segurança, basta extinguir a dinastia do principe que os dominava, porque, quanto às demais coisas, mantendo-se suas antigas condições e não havendo disparidade de costumes, podem os homens viver tranqüilamente, como fizeram de fato a Borgonha, a Bretanha, a Gasconha e a Normandia, que há tanto tempo pertencem à França e, tendo costumes semelhantes, conquanto haja alguma diferença de lingua, podem facilmente se ajustar. (pp.8-9).

A Itália, então, é para Maquiavel uma grande província, uma região que. ainda que com algumas especificidades de língua e costumes locais, mantinha uma unidade étnica, cultural e histórica. Esse último dado é especialmente importante. A Itália, então dividida e por isso mesmo invadida, pilhada, violentada, escravizada e vilipendiada, fora por séculos o umbigo do mundo, a sede de um Império de proporções globais - para a época - e os italianus, descendentes diretos dos romanos, traziam ainda na memória os tempos de glória que tanto contrastavam com a patética situação em que se encontravam, governados por príncipes incapazes de reavivar o antigo brilho da pátria. Donde, para um italiano, especialmente um italiano como Maquiavel, a restauração da unidade política da Itália, que the permitisse libertar-se do jugo dos "bárbaros" - palavra que era usada pelos romanos para definir os estrungciros, aqueles que não falavam o Latim --, fosse um dos projetos mais dignos, se não $o$ mais digno, de se levar adiante. Isso fica muito claro no primeiro parágrafo do seu Discurso ou Diálogo Sobre a Nossa Lingua (1518), quando escreve:

Sempre que pude honrar minha pátria, ainda que isso me sobrecarregasse ou me pusesse em perigo, fillo voluntariamente, porque um homem não tem ohrigação 
maior em sua vida do que para com ela, devendo primeiramente a ela a existência e, além disso, tudo aquilo que de bom a fortuna e a natureza nos hão concedido; e verm a ser essa obrigação tanto maior naqueles que tiveram a sorte de pertencer a pátria tão nobre. $^{\text {? }}$

Mais: o próprio interesse, demonstrado por essa obra, na identificação do que, para além dos dialctos locais, fosse efetivamente a lingua italiana, já indica uma preocupação com a unidade da Itália, pois a fragmentação do idioma em dialetos locais dificultaria ou mesmo inviabilizaria qualquer projeto de unificação política como o próprio Maquiavel afirma n'O Principe. E í esse projeto de unificação política que, aparentemente, dá sentido global à obra de Maquiavel, permitindo, inclusive, como afirma Aron, ${ }^{8}$ responder à aparente contradição, identificada por Rousseau, entre a opção republicana dos Discursos sobre a Primeira Década de Tito Livio e a análise e prescrição do melhor modus operandi para a instauração e manutenção de tiranias d'O Principe: por mais que Maquiavel preferisse a liberdade, ele sabia que ela não scria capaz de fornccer as bases, na condição em que sc encontrava a Itália à época, para o projeto de unificação; um governo que não tivesse a seu dispor grande força armada e que não fosse capaz de domar, pela força ou pela astúcia, os interesses mesquinhos de nobres, ricos e pobres acabaria ou se esboroando devido aos conflitos internos ou sendo dominado por potências estrangeiras. 'Assim, perseguir o ideal da liberdade, por si só louvável em todos os aspectos, deixa de ser, na visão de Maquiavel, o excrcício da virtù, pois na situação concreta conduziria a um resultado oposto do pretendido. O que não-significa que, alterado o panorama. não se

7. Traduzido livremente do original: "Sempre che io ho potuto onorare la parria mia, eziandio con mio carico et periculo, I'ho fallo volentieri; perche l'uomo nun ha maggiore obbligo nella vita sua che con quella. dependendo prima da essa l'essere e. di poi, tullo quello che di buono la fortuna e la natura ci hanno conceduto; $c$ lanto viene a esser maggiore in coloro che hanno sortito patria piu nobile"

8 . No prefácio de sua autoria, incluso na edição d'O Principe referida na nota 2.

9. Isso é o que transparece na seguinte passagem: "... se um principe quiser manter-se no poder. freqüentemente serú forçado a não ser bom, pois quando é corruptu aquela comunidade - seja elao povo. os soldados ou os grandes da qual julgues ter necessidade para consenta-te no poder, convimte alender ao s'u humor para satisfazê-la, c'então as boas obras poderão te ser prejudiciais"(p. 93). 
devesse buscar tão nobre ideal, o que, na visão do florentino, só se alcançaria na república.

Essa interpretação, por sua vez, ressalta a segunda característica marcante de Maquiavel: a razão da escolha do despotismo, no projeto esquematizado n'O Príncipe, como melhor forma de governo para a situação concreta que observava na Itália da época deriva de sua visão inabalavelmente realista. É o que se examina a seguir.

2. "La veritá effettuale della cosa"

A preocupação de Maquiavel com uma análise realista do seu objeto de estudo aparece já com certa evidência na divisão dos temas d' $O$ Principe, que começa com uma análise detalhada dos tipos de principado, feita em função das facilidades e dificuldades que cada tipo opõe à sua conquista e manutenção, prossegue examinando e classificando os diversos tipos de exércitos e de seu valor para o príncipe e termina com uma confrontação entre as diferentes atitudes que um principe pode tomar em face dos seus súditos e de outros príncipes, com o fím de identificar quais seriam mais vantajosas. O notável é que em nenhum momento o florentino se dedica a perscrutar as razões pelas quais algo é como é, somente o interessando esclarecer e definir esse ser das coisas, para nele basear as suas recomendações sobre o que um príncipe de virtù deve fazer para conquistar e conservar seu poder. Essa preocupação em conhecer algo de forma a fornecer parâmetros para a ação dá à obra, no dizer de Tércio Sampaio Ferraz Jr., um caráter dogmático, completamente oposto a uma investigação zetética. $^{10}$

O realismo de Maquiavel, todavia, não é algo implícito, que se possa apenas deduzir dos temas e sua distribuição n’O Principe. É algo abertamente confessado, inclusive reclamado pelo autor como sendo a nota de novidade de seu trabalho diante das muitas obras anteriormente escritas sobre o mesmo assunto."

10. Para a distinção entre zetética e dogmática como dois possiveis enfoques de investigação de um problema, cf. FERRAZ JR., Tércio Sampaio. Introdução ao Estudo do Direito: Técnica, Decisão, Dominação. 4 ed. São Paulo: Atlas, 2003, p. 39-43.

11. "Como sei que muitos jú escreveram sobre este assunto, temo que, escrevendo eu lumbèm, seja considerado presunçoso, sobretudo porque, ao discutir esta matéria, ajastar-me-ci das linhas rraçadas pelos outros. Porém, sendo meu intento escrever algo itil para quem me ler. parece-mc mais conveniente procurar a verdade efetiva da coisa do que uma imaginação sobre ela" (p. 73). 
Mais: na opinião de Maquiavel, qualquer visão que sc afaste de um realismo estrito, que deixe de buscar a "veritá effettuale della cosa" (p. 73), a verdade efetiva da coisa, está fadada a fornecer conclusões equivocadas, perigosas para o estado. ${ }^{12}$

Ocorre que o realismo maquiaveliano é justamente uma das aparentes contradições internas d'O Principe: logo após fazer sua profissão de fé no estudo das coisas como elas são e não como deveriam ser, propondo-se a deixar de lado as "coisas imaginadas acerca de um principe e [a discorrer] sobre as verdadeiras" ( $p$. 73), passa a examinar não as reais qualidades que um príncipe efetivamente tem, mas aquelas que as demais pessoas imaginam que ele tenha, ${ }^{13}$ tendo-se afirmado realista, passa a falar de ilusões. Essa contradição não passou despercebida ao editor do tex to original italiano no qual se baseou a tradução brasileira ora utilizada, que fez constar a seguinte nota:

Observe-se a inversão realizada por Maquiavel: após denunciar a ineficácia do discurso tradicional, tachado de "imaginário" e oposto à "verdade efetiva das coisas" ele se volta para o problema da imagem do príncipc, de sua "fenomenologia" e não do que ele seja em si mesmo. Ironicamente, o mundo imaginário dos pensadores se une ao imaginário popular acerca do principe (p. 173).

Será correta tal crítica? Ou-não seria o mais rematado realismo estudar as aparências do principe quando é com base em nas aparências que percebem que os homens determinam seu comportamento? A sociologia atual, baseando-se nos estudos

12. "Muitos imaginaram republicas e principados quc jamais foram vistos c' que nem se soube se" existiram na verdade. porque há tamanha distancia entre como se vive e como se deveria viver, que aquile que trocar o que se faz por aquilo que se deveria fazer aprend antes sua ruina do que sua preservação" (p. 73).

13. "Deixando de lado, pois, as coisas imaginadas acerca de um principe e discorrendo sobre as verdudeiras, afirmo que quando se fala dos homens, e principalmente dos principes, por estarem em posição mais elevada, eles se fazem notar por cerlas qualidades quc lhes trazem reprovação ou louvor. Assim, um é considerado liberal e outro mis èrável; um é considerado pródigo e outro gananciosu; um cruel e outro piedoso; um falso e outro fiel; um efeminado e pusilânime outro feroz e corajoso; um modesto e outro soberbo; um lascivo 'outro casto: um integro e vutro astuto; um duro e outro maleável; um ponderado e outro leviano: um religioso e outro incrédulo e assim por diante."(p. 73-74). 
da teoria da comunicação, vê nas relações sociais relações de comunicação, nas quais os comportamentos humanos são definidos como um estar em situação com os outros seres humanos: estar em situação significa essencialmente trocar mensagens com outros interlocutores. Essas mensagens se baseiam em expectativas do emissor em relação ao destinatário quanto ao modo como este receberá a mensagem, sendo csta expectativa, por sua vez. baseada numa expectativa prévia do emissor quanto à expectativa que dele tem o destinatário. Tais expectativas, todavia, não se baseiam necessariamente em dados concretos, mas geralmente, uma vez que raramente conhecemos bem todos os interlocutores com quem trocamos mensagens em nossa vida social. em simples impressões que formamos a partir das aparências do outro. ${ }^{14}$ Fssas expectativas podem se confirmar ou não, sendo justamente esse processo de seleção de expectativas e confirmação/desilusão que progressivamente nos permite conhecer o outro. Esse conhecimento, entretanto, jamais chega a um ponto onde se prescinde do uso das aparências como base das expectativas que dele fazemos. podendo-se dizer que sempre haverá uma margem irredutível de desconhecimento do outro nas nossas relações mútuas.

Assim, por exemplo, numa reunião de negócios, sabemos que a ruupa que usamos já transmite algo de nós para os outros participantes, e sabemos também que em tal situação é muito importante passar a mensagem adequada; por isso, buscamos usar uma roupa que transmita essa mensagem. Todavia, se nós não conhecemos as outras pessoas a ponto de saber qual tipo de vestimenta elas considerariam adequada para a ocasião, decidiremos com base numa expectativa fundada em indícios que delas temos e que nos permitam fundar uma escolha: sua área de atuação profissional, sua nacionalidade, sua classe social etc.; assim, na falta de um conhecimento mais concreto do outro, resta-nos operar com base em préconceitos a respeito do tipo de pessoa que achamos que ele seja. Assim. sabendo-se que o outro seja um industrial bem posicionado no mercado e nós, advogados buscando fazê-lo cliente de nossa banca, nossos pré-conceitos nos farão escolher uma vestimenta que transmita seriedade, segurança e profissionalismo, que identificamos no traje social. A escolha do traje correto é, pois, uma decisão fundada na nossa

14. L'ma descrição mais completa dessa visão de relações comunicativas, orientada para uma definição de norma como norma-comunicação. encontra-se em FERRAZ JR., Tércio S. Introdução.... p. 102-105. 
expectativa acerca de qual seja a expectativa do outro quanto à vestimenta de uma pessoa séria, segura e profissional.

Se assim é, o príncipe está em situação com os súditos, e vice versa. Um ato do principe, especialmente uma ordem, transmite uma mensagem, mas o seu cumprimento ou não por parte dos súditos também o faz. E é exatamente na definição do conteúdo dessa última mensagem que reside a incrivel atualidade do pensamento quase quincentenário de Maquiavel: o que fará um súdito comunicar sua submissão ou rebeldia às ordens do príncipe será sempre a expectativa que tenha do modo como o príncipe reagirá à sua decisão. O súdito, contudo, não conhece o príncipe a ponto de saber com certeza qual seria sua resposta; deve, então, fundar sua escolha no que as aparências que consegue captar do soberano the transmitem. Logo, para um príncipe, terá menos importância o que ele realmente é, isto é, quais seus vícios ou virtudes concretos, do que aquilo que ele aparenta ser, pois aos olhos de quem não o conhece e quem poderá dizer que efetivamente conhece um príncipe? - a sua aparência é o seu efetivo ser. ${ }^{15}$ E se é assim, um realista como Maquiavel não pode deixar de estudar a aparência do príncipe, desprezando seu ser concreto, pois essa é a "verdade efetiva das coisas" 16

Com isso se pode interpretar, sob uma luz diferente, a seguinte passagem. constante da dedicatória d'O Príncipe a Lorenzo de Medici:

Espero que não seja considerado presunçoso que um homem de baixa e infima condição ouse examinar $e$ regular o governo dos príncipes; pois, assim como os que desenham as paisagens se colocam embaixo, na planicie, para ohservar a natureza dos montes e dos lugares elevados: e, para examinar a forma dos lugares baixos, se colocam no alto, em cima dos morros; assim, também, para conhecer bem a natureza dos povos, é preciso ser

15. "Os homens, em geral, julgam as coisus mais pelos olhos que com as mãos, porque todos podem ver, mas poucos podem sentir. Todos vêem aquilo que pareces, mas poucos sentem o que és; e istes poucos não ousam opor-se à opinião da maioria, qu' tem, para defendê-lu, a majestade do estado" (p. $85)$.

16. “... o vulgo esia sempre voltado para us uparèncias e para o resultado das coisus, enão há no mundo senão o vulgo" (p. 85-6). 
principe, e, para conhecer a natureza dos príncipes, é preciso ser do povo. (p. 130).

Duas conclusões se podem tirar desse trecho: num primeiro momento, temos aqui Maquiavel afirmando suas qualificações para escrever tal obra: homem nascido na "planície" sem sangue nobre, filho de advogado e poetisa, esteve durante muito tempo no alto dos "morros" participando do governo de Florença; conhece bem, pois, povo - que viu do alto -, e príncipes - que viu tanto de baixo, antes de ascender ao governo e agora, demitido e perseguido, quanto na sua experiência de quase quinze anos de missões junto a governos estrangeiros - o que lhe credencia a escrever um livro que. examinando a realidade do exercício do poder num principado, prescreve condutas adequadas ao príncipe. Mais do que isso, porém, tal trecho marca o abismo que separa o príncipe dos súditos, de tal modo que nenhum conhecimento intimo é possivel: numa realidade dessas, as ações, tanto de um quanto dos outros. só podem ser pautadas por aparências, donde a desnecessidade da análise das qualidades que o príncipe concretamente possui, devendo-se antes estudar as que ele aparenta ter, isto é, a imagem que ele passa para os súditos.

Um dos melhores exemplos disso, que se pode extrair d'O Príncipe, é justamente a questão de ser melhor a liberalidade ou a parcimônia: Maquiavel afirma que o ideal seria ser sempre liberal, mas conseguir tal fama exige constantes e notáveis exibições de desapego ao dinheiro; na primeira oportunidade em que não se exibe liberalidade, ou se a exibe de maneira controlada. a fama de mísero é inevitável. Logo, ser conhecido como liberal independe do efetivamente ser liberal: pode-se sê-lo e ainda assim ter a fama de misero: por outro lado. pode-se ser mísero e, através de atos intencionais, garantir uma reputação de liberal. Daí que se deve estudar a reputação de liberal ou mísero, e analisar as suas conseqüências, bem como as dos atos que nelas resultam, para o objetivo de manutenção do poder do estado.

É interessante perceber que, na obra de outro expocnte do realismo, a idéia de aparência é igualmente importante: no Cap. XIII do Leviatã, Thomas Hobbes, na sua descrição do estado de natureza, deixa transparecer que a razão que liva um homem a um conflito declarado com seu semelhante não precisa ser uma ameaça concreta, mas pode ser uma antecipação, ou mesmo a imaginação, de uma ameaça 
ainda inexistente. ${ }^{17} \mathrm{O}$ estado de guerra de todos contra todos, então, nasce da suspeita generalizada que o homem tem em relação a seu semelhante, que não reflete necessariamente um estado de coisas real. e que o faz estar constantemente se preparando para um eventual conflito, suspeita essa que só cessa quando se instaura um poder superior capaz de manter todos os homens estarrecidos e amedrontados. ${ }^{18}$

Com base nessas duas características de Maquiavel que acima se buscou explicitar, seu patriotismo e sua visão realista do mundo, pode-se tentar identificar um motivo para a redação d'O Principe que oriente uma interpretação da obra. Podemos afirmar que o projeto final de Maquiavel, aquele para o qual ele deseja contribuir, é a restauração, ainda que não da antiga glória italiana - quando ainda se chamava Roma -, pelo menos da unidade e da independência da Itália, então dividida e subjugada por potências estrangeiras. Sua visão realista. por outro lado, lhe dá a convicção de que não se deve esperar que as coisas sejam como devem ser, mas aceitá-las como eftivamente são e agir de acordo. O projeto de unificação exige. então, um príncipe que saiba agir de acordo com as exigências concretas postas por seus objetivos; essas exigências, porém, nem sempre coincidem com o que prescreve a moral, surgindo a questão de saber, no caso concreto, qual deve prevalecer. Essa escolha não é problema para o florentino: quando as exigências para a manutenção do

17. "And from this diffidence of on' another, there is no way for any man to secure himself so reasonable as anticipation; that is, by force, or wiles, to master the persons of all men he can so long till he see no other power great enough to endanger him: and this is no more than his own conservation requireth, and is generally allowed. Also. because there be some that, taking pleasure in contemplating their own power in the acts of conquest. which they pursue farther than their security requires, if others. that otherwise would be glad to be at ease within modest bounds, should not by invasion increase their power, thev would not be able, long time, by standing only on their defence, 10 subsist. And by consequence, such augmentation of dominion over men being necessary 10 a man's conservation, it ought to be allowed him" (Leviathan, Cap. XIII)

18. "Hereby' it is manifest that during the time men live without a common power to keep them all in awe, they are in that condition which is called war: and such a war as is of every man against every man. For war consisteth not in batlle only, or the act of fighting. but in a tract of time. wherein the will 10 contend by battle is sufficicmly known (...) so the nature of war consisteth not in actual fighting, bu in the known disposition thereto during all the time there is no assurance to the contrary. All other time is peace." (Leviathan, Cap. XIII) 
estado se chocam com as exigências da moral, que se preserve o cstado. ${ }^{19}$ Esse não era, também, um problema para os príncipes da época, dado o registro histórico de seus atos, donde não ser necessário instrui-los nessa escolha crucial: o que faltava aos príncipes da época, e isso é explícito n’O Príncipe, é a capacidade de determinar a ação adequada para o fím de manutenção do poder estatal. ${ }^{20}$ Essa capacidade é chamada por Maquiavel de virtù, e é o primeiro dos dois conceitos-chave que se deve analisar para uma compreensão da sua obra.

\section{Virfù: Virtude não necessariamente virtuosa.}

Chega-se. assim, a um dos conceitos centrais d'O Principe, que também é o mais enigmático e o que, por isso mesmo, mais forneceu ocasião para polêmicas: a virtù maquiaveliana. É um conceito central, pois é somente através dela que se pode alcançar estabilidade no poder do estado, ainda que, como se verá adiante, cla não seja uma garantia absoluta disso; é um termo enigmático pois, além de não se encontrar dele uma definição na obra, ele é claramente utilizado com sentidos diversos em diferentes passagens do texto. ${ }^{21}$ É equívoco e ambíguo: numa determinada passagem do texto, Maquiavel chega a empregar quatro acepções

19. "Sei que vão dizer que seria muito louvável que um principe, dentre lodas as qualidades acima. possuisse as consideradas boas. Não sendo isso porèm inteiramente possivel, devido às próprias condições humanas que não o permitem, necessita ser suficientemente prudente para evitar a infâmia daqueles vicios que lhe tirariam o estado e guardar-se, na medida do possivel, daqueles que nâ lhe furiam perdê-lo; se não o conseguir, entretanto, poderá, sem grande preocupação, deixar estar. Também não deverá importar-se de incorrer na infâmia dos vicios sem os quais the seria dificil conservar o estado porque, considerando tudo muito bem, encontrar-se-á alguma coisa que parecerá virtù $e$, sendo praticada, levaria à ruina; enquanto uma outra que parecerá vicio, quem a praticar poderá alcançar segurança e bem-estar" (p. 74)

20. "Na Itália, não falta matéria onde introduzir novas formas. Aqui existc grande virti em todos as membros, embora ela fulte nas cabeças (...) E tudo resulta da fraqueza dos chefes" (p. 125). Vejam-se, além disso, as resenhas dos erros estratégicos dos príncipes italianos feitos nos caps. XII e XXIV d'O Principe.

21. O termo virtu (e suas variações virtuoso, virluosamenti etc.) aparece 71 vezes no decorrer d'O Principe. Num levantamento feito com base na edição em italiano, o autor identificou pelo menos 11 sentidos diferentes em que o termo é utilizado. Mesmo o significado que neste trabalho se defenderá como sendo, dentro desses. o que denota a virtù maquiaveliana, apesar de ser o mais freqüente, comporta tantas variações que só pode ser captado mediante uma leitura conjunta de todas as suas possiveis nuances. 
diferentes de virlù num único parágrafo! ${ }^{22}$ Não espanta que os tradutores da obra do florentino, reconhecendo a imensa dificuldade da tarefa de verter o termo mantendolhe inalterado o significado original, optem por deixá-lo em italiano.

A virtù pode ser entendida, num primeiro momento, como virtude moral, em oposição a vício, e esse é o sentido usualmente dado ao termo. Maquiavel, é fato, emprega o termo com essa conotação em algumas passagens do texto, ${ }^{23}$ mas a simples leitura dos Caps. XV-XIX, que aconselham o Principe à prática de atos que jamais poderiam ser considerados moralmente virtuosos, já desautoriza tal interpretação. Ademais, fosse esse o significado da virtù maquiaveliana, dificilmente se encontraria justificativa para a escolha do facinoroso Cesare Borgia como modelo de príncipe virtuoso.

Etimologicamente, virtù deriva do latim virıus, que significa força corpórea, ânimo, valor, bravura, coragem, força de alma, energia, boas qualidades morais, mérito. Virlus, por sua vez, deriva de vir, étimo que significa homem, varão, exprimindo as qualidades masculinas. Também nessa acepção, relacionada à potência, à força de algo, encontramos a palavra virtù n'O Principe, ${ }^{24}$ mas, novamente, ela nãoexprime perfeitamente o sentido da virtù maquiaveliana, pois frequentemente o ato virtuoso depende menos do vigor físico do que da astúcia e da prudência, que são qualidades mentais que se atribuiam também às mulheres.

Semelhantes resultados terão todas as tentativas de buscar o sentido exato da virtù maquiaveliana perfeitamente evidenciado num único uso do termo. $\mathrm{O}$ que a leitura atenta da obra revela é que esse sentido último somente pode ser

22. "[Referindo-se a Agátocles Siciliano] Quem considerar, portanto suas ações e sua vida [no original, le azione e virtù di costui] não verá coisa alguma. ou pouca. que se possa atribuir à fortuna: (...). Não se pode propriamente chamar de virtù o fato de assassinar seus concidadãos, trair os amigos, não ter fé. piedade nem religião. Deste modo pode-se adquirir o poder, mas não a glória. Mas, se considerarmos a virtù com que Agátocles entrou e saiu dos perigos e a força de seu ânimo ao suportar e superar as adversidades, não por que ele devia ser julgado como inferior a qualquer excelente capitão. Contudo. sua feroz crueldade e desumanidade, mais a sua infinila malvadeza, não permitem que seja celebrado entre os homens excelentes. Não se pode, portanto, atribuir à fortuna ou à virtù oque sem una nem outra foi conseguido" (p. 38).

23. Veja-se, por exemplo, a segunda ocorrência de virtiu no trecho transcrito na nota anterior.

24. [Exortando o Príncipe a seguir os exemplos de homens grandes e/ou excelentes como exercicio de virfiu " "Mesmo não alcançando sua virtu, deve pelo menos mostrar algum indicio dela e fazer como os arqueiros prudentes que, julgando muito distantes os alvos que pretendem alcançar e conhecendo bem o grau de exatidão de seu arco [no original, e conoscendo fino a quanto va la virui de loro arco]. orientam a mira para bem mais alto do que o lugar destinado..." (p. 23). 
alcançado através de uma inferência baseada na consideração conjunta dos vários sentidos específicos em que a palavra é empregada na obra, descartando-se aqueles totalmente incompatíveis - como é o caso com o sentido de virtude moral -. e as instâncias em que o vocábulo é usado com ironia.

Assim, vê-se que na sua primeira ocorrência, a virtù é elencada como uma das maneiras de se conquistar o poder..$^{25}$ Mais à frente, clogiando os antigos romanos por não se acomodarem após as vitórias, estando sempre prontos a gucrrear antes que um potencial inimigo se tornasse uma ameaça maior, atribui essa caracteristica à sua virtù e prudência. ${ }^{26}$ Mais adiante, temos que o grau da virtù do Principe é inversamente proporcional à dificuldade que ele terá para manter seu estado. ${ }^{27}$ Na página seguinte encontramos a virtú como a habilidade de identificar o momento certo de agir, cujo resultado é a honra e a felicidade da pátria. ${ }^{28}$ Viramos mais uma página e lemos que a virtù é uma caracteristica típica dos príncipes. ${ }^{29}$ No capitulo seguinte, o célebre capítulo em que relata a trajetória do Duque Valentino, Maquiavel nos diz que a virtù e o engenho podem fazer de um cidadão comum um bom comandante/governante, ${ }^{30}$ caso tenha ele ascendido aos poder pela fortuna ou pelas armas de outrem, pois um homem virtuoso saberá "rapidamente se preparar para conservar aquilo que a fortuna [Ihe] colocou nos braços" (p. 28); o final infeliz de

25. "Os dominios assim formados estão habiluados a viver sob um principe ou ascr linres. Ese adquirem ou com armas de outrem, ou com as próprias, graças à fortuna ou à virlü." (p. 3).

26. "Não lhes agradou jamais aquilo que está na boca de todos os sábios dos nossos tempos - gozar os beneficios do tempo -, mas sim os beneficios de sua virtù e prudencia. porque u tempo leva adiante todas as coisas e pode trazer consigo lanto o bem quanto o mal, e tanto o mal quanto o bem" (p. 12-3).

27. "Digo, portanto, que nos principados completamente novos, onde há um novo principe, existe maior ou menor dificuldade para mantê-lo conforme seja maior ou menor a virti de quem o crnquiston" (p. 23).

28. [Referindo-se aos melhores dentre os que se tornaram principes pela virrì e não pela fortunaMoisés, Ciro, Rômulo e Teseu] "Examinando suas ações e suas vidas, veremos que não receheram da fortuna mais do que a ocasião, que lhes deu a matéria para introduzirem a forma que lhes apronvesse. $E$ sem ocasião a virtù de seu ânimo se teria pérdido, assim como. sem a virtù a ocasião teria seguido em vão (...) Essas ocasiões, portanto, tornaram aqueles homens afortunados, enquanto sua excelente virtù fez com que reconhecessem a ocasião. Com isso, trouxeram honra e felicidade a suas pátrias" (p. 24-5).

29. [Sobre Hierão de Siracusa] Foi de tamanha virtù, mesmo enquanto cidadào particular, que sobre ele se dizia que quod nihil illi derat ad regnandum praeter regnum [nada lhe fultcria para reinar. excelo um reino] (p. 26).

30. "Não sabem porque, a menos que sejam homens de grandte engenho é viru não é razoável que saibam comandar tendo sempre vivido como particulares" (p. 27). 
Valentino, todavia. serve para mostrar que a virlù, em certas ocasiões, nada pode contra os caprichos da fortuna. ${ }^{31} \mathrm{Na}$ seqüência, tratando dos que chegaram ao poder por meio de atos criminosos, o florentino nos mostra que a virtú, embora não observe os limites morais, não se confunde nem com ação celerada ${ }^{32}$ nem, no caso dos principados civis, com uma "astúcia afortunada" 33 A virtù é, ainda, tida como uma qualidade dos bons generais, a qual se torna um risco para o príncipe quando esse capitão é mercenário. ${ }^{34}$ Finalmente, a virtú é tida como a qualidado que permite ao principe - dentro de certos limites - resistir às mudanças danosas trazidas pela fortuna. $^{35}$

Dessa imensa variedade de significados específicos, algumas constantes podem ser ressaltadas: a) é um atributo fundamentalmente político, que deve ser possuido por aqueles que governam os estados; b) em quase todos os usos, a palavra virtù se refere a uma capacidade de se antecipar, de prever acontecimentos futuros e para eles se preparar, escolhendo os meios adequados; c) a sua independência de quaisquer prescrições morais faz com que essa adequação se faça apenas em função dos fins visados, e posteriormente, e não de antemão, segundo a natureza em si dos meios escolhidos, donde a importância da capacidade de antecipação do homem

31. "Por outro lado, Cesare Borgia, vulgarmente chamado Duque Valentino. conquistou o estado com a fortuna do pai e com ela o perdeu, apesar de ter usado de todos os atos e de ter realizado todas as coisas que um homem prudente e valoroso deveria ter feito..." (p. 28). Esta passagem contradiz o rclato que Maquiavel faz da derrocada do Borgia, pois atribui sua "ruina final" ao fato de ter acreditado na promessa de aliança de Julio Il e tê-lo ajudado a se eleger Papa em sucessão a Alexandre VI; da leitura do ocorrido, tem-se que a queda de Valentino deveu-se mais a um erro estratégico seu do que a um acidentu do acaso.

32. "... ainda existem dois outros modos de se passar de simples particular a principe que não se devem apenas nı̀m à fortuna nem à virtù (...) Esses dois modos são: ou ascender ao principado por via celerada $\mathrm{c}$ nefanda ou um cidadão particular tornar-se principe de sua pátria com o favor de seus concidadãos" (p. 37).

33. "... tratando do outro caso, em que um cidauão se torna principe de sua pátria, não por alos criminosos nem outras violências intoleràveis, mas pelo apoio de seus concidadãos (o que se pode chamar de principado civil; para alcançá-lo não é necessário ter muitu virtù, nem muita jurtuna, mus antes uma astucia afortunada)..." (p. 43).

34. "Os capiläes mercenários ou são homens excelentes nas armas ou não o são. Se o forem, não poderá confiar neles, porque sempre aspirarão a uma grandeza própria (...) e. se não forem capiläes valorosos [no original, se non è il capituno virtuoso], por isso inesmo te arruinarão" (p. 58).

35. "O mesmo acontece com a fortuna, que demonstra a sua força onde não encontru uma virù ordenada, pronta para lhe resistir $e$ volta o seu impelo para onde sabe que não foram erguidos diques para contê-la" (p. 120). 
virtuoso; e c) esses meios envolvem necessariamente, embora não exclusivamente, o uso ou possibilidade de uso da força.

A partir dessas características comuns, chegamos à seguinte $-e$ tentativa - definição para a virtù maquiaveliana: a capacidade de determinar, de acordo com as necessidades do momento presente e em face de seus possiveis desdobramentos futuros, o curso de ação mais apropriado para a manutenção do estado, mesmo violento, se necessário for, sem levar em conta julgamentos morais que possam impedir que as medidas exigidas sejam adotadas. O príncipe de virtù, então, será aquele que, sabendo "não ser bom" (p. 93), não hesita em tomar quaisquer medidas necessárias para se precaver de problemas futuros, nem em "incorrer na infâmia dos vícios sem os quais the seria difícil conservar o estado" (p. 74). Dissimulada, escondida no texto, sem nenhuma referência direta à virtù - de fato, no meio de um hiato de 9 páginas em que o termo não aparece -, é exatamente essa a descrição que Maquiavel faz do que deve um principe fazer:

Precisa, portanto, ter o espírito preparado para voltar-se para onde lhe ordenarem os ventos da fortuna e as variações das coisas e; como disse acima; não se afastar do bem, mas saber entrar no mal, se necessário (p. 85).

Não se confunde, assim, a virtì com a prudência, pois ela vai além desta, na medida em que envolve não apenas a escolha do caminho a ser seguido em função das conseqüências dessa escolha, mas também a previsão de problemas futuros e a escolha dos meios para evitá-los ("ter o espírito preparado"). Não se confunde, também, com a astúcia e a dissimulação, que são apenas táticas que o príncipe de virtù pode lançar mão dependendo da necessidade, sendo a virtù mais especificamente a capacidade de identificar o momento em que elas são necessárias ou o momento em que elas são contraproducentes - e de não ter escrúpulos em utilizá-las ("saber entrar no mal, se necessário"). Mas isso não identifica a virtù com a vilania, com a scelleratezza sem bridas, pois deve o príncipe "não se afastar do bem", entendido o "bem" não no seu sentido moral, mas do ponto de vista do resultado 
buscado com a ação, qual seja, a manutenção do poder, ${ }^{36}$ há, pois, limites ao que o príncipe pode fazer. que são dados pelo fim último de conservação do estado.

Mas, se a qualidade de "bom" ou "mau" de um ato só se dá em vista dos resultados que ele produz, sabendo-se ser praticamente impossível prever com certeza todos os possíveis desdobramentos futuros, ${ }^{37}$ chega-se, paradoxalmente, ao limite da própria virtù: a incerteza do futuro, ou, na figura utilizada por Maquiavel, os caprichos da Fortuna. É ela, Fortuna, o segundo conceito-chave para decodificar a obra de Maquiavel, que se analisa a seguir.

\section{A Fortuna e sua Roda Implacável.}

A fortuna é o segundo conceito central da obra de Maquiavel, e aquele que dá a dimensão tanto da importância da virtù quanto de seus limites práticos. Como não podia deixar de ser, é também a palavra "fortuna" um termo ambíguo, aparecendo no lexto em várias accpções distintas, ora como sinônimo de "sorte" ora como equivalente de "sucesso", ora - e é nesse sentido que analisaremos o termo personificada na figura da antiga deusa romana do destino, Fors, como a força que determina os acontecimentos, benéficos ou não, que se apresentam aos homens e, especialmente, aos príncipes.

A figura da Fortuna i um iconc importante durante toda a Idade Média, e sua importância deve-se, em grande medida, à obra de Boetius, De Consolatione Philosophiae. ${ }^{38} \mathrm{Na}$ sua representação pictórica mais freqüente, ela aparece como uma

36. O melhor exemplo dessa regra, sem dúvida, é o do sangrento destino de messer Remiro de Oroo. intendente de Cesare Borgia na Romanha: enquanto era necessário um governo brutal para pacificar a provincia e "reduzi-la à obediência", seus atos de crueldade eram úteis ao Borgia: pacificada a Romanha, todavia, a continuação desses atos seria prejudicial a Valentino, pois poderia tomá-lo odioso aos olhos do povo e por em risco o estado, logo, para desvencilhar-se dessa reputação, mandou executar Remiro em praça pública. Tem-se, então, que um mesmo curso de ação pode ser justificado num momento e não em outro, mas nunca em função de sua moralidade ou imoralidade, mas sim do ponto de vista de sua utilidade para o fim de manutenção do poder do estado.

37. "Não se acreditc que eslado algum possa sempre tomar decisões seguras. Pelo contrário, devese sempre levar em conı qu as decisões são todas dúbias, pois isto se insere na ordem das coisas, $e$ não se consegue jamais escapar de um inconveniente sem recair em outro" (p. 108).

38. COSTA. Ricardo da e ZIERER. Adriana. Boécio e Ramon Llull: A Roda da Fortuna, princípio e fím dos homens. Convenit Internacional - Edição Eletrônica, online, São Paulo, n. 5. 2000. Disponivel em: $<\mathrm{http} / / \mathrm{www}$.hottopos.com/convenit5/08.htm>. Consultado $\mathrm{cm} 20 / 09 / 2004$. ISSN $1517-6975$ 
mulher girando, por meio de um mecanismo. geralmente uma manivela, uma roda onde se distinguem quatro seções: na primeira, à esquerda. temos um homem que escala a roda, primeiro com roupas comuns, depois vestido como nobre, com o braço direito erguido: na segunda, o topo da roda, o mesmo homem se encontra sentado, ricamente vestido e portando uma coroa; na terceira, esse homem, seguindo o movimento, começa a perder o equilíbrio até que, já quase de ponta-cabeça, escapaIhe a coroa; na terceira, o homcm. despojado de seu manto nobre e com a cabeça descoberta, aparece ora esmagado pela própria roda, ora nela pendurado, ora estatelado no chão, já não mais fazendo parte do ciclo.

Os ânimos em relação à fortuna variaram muito no tempo, tendo ela sido adorada na antiguidade, tanto pelos gregos, que a chamavam $T y c h e$, quanto pelos Romanos, que para cla dedicaram um templo à beira do Tibre; na obra de Agostinho de Hipona, temos a fortuna como uma deusa e, como tal, sempre bondosa, de tal sorte que quando a fortuna se torna má, há que se perguntar se ela não se converteu num demônio; na literatura posterior, é sempre vista com desconfiança e até mesmo com desprezo. ${ }^{39} \mathrm{Na}$ obra de Maquiavel ela adquire uma feição diferente, diferente da velha bruxa que seus contemporâneos pintavam, surgindo jovial, ${ }^{40}$ além de estar atrelada a um resquicio de esperança, de que a sua roda continue girando e leve quem já esteve no topo e caiu de volta ao alto, o oposto do fatalismo embutido na concepção tradicional.

No imaginário do Medievo, a Fortuna aparece associada à discussão de quanto do que sucede ao homem pode ser atribuído ao destino e quanto decorre exclusivamente das escolhas por ele feitas. Maquiavel se referc a esse problema na abertura do Cap. XXV d'O Principe:

Não ignoro que muitos foram e são da opinião de que as coisas desse mundo são governadas pela fortuna e por Deus, e que os homens prudentes não se lhes podem opor, $e$ até que não têm rumédio algum contra elas. Por isso, poder-se-ia julgar que não devemos incomodar-nos $215-6$.

39. DE GRAZIA, Sebastian. Maquiavel no Inferno. São Paulo: Companhia das Letras, 1993, p. 40. Ihid., p. 223. 
demais com as coisas, mas deixar-nos governar pela sorte. (p. 119).

Maquiavel admite que se sente inclinado a aceitar esse ponto de vista, mas afirma que o livre-arbítrio humano tem sua importância, embora seja por vezes suplantado pela força da fortuna. ${ }^{41} \mathrm{Na}$ sua visão, o homem pode evitar muitos dissabores preparando-se para as surpresas que a fortuna the preparar, donde a comparação desta com um "rio impetuoso" cujos danos podem ser evitados ou ao menos minorados por homens previdentes que construam diques e canais para contêlo. Contra as inundações causadas pela fortuna, somente podem os homens precaverse com a virtù.

Aqui a etimologia da palavra coincide em tudo com a ilustração utilizada por Maquiavel. Virtù é a força masculina (vir), que deve ser aplicada à fortuna. que é mulher, para dominá-la; só assim, com violência, ela se deixa vencer. ${ }^{42}$ $\mathrm{O}$ homem de virtù. assim, através de sua prudência, de sua capacidade de se antecipar aos acontecimentos futuros e de não se conter por julgamentos morais, agarra a Deusa pelo braço e a impede de continuar a girar a roda: essa a violência que a conquista, e que garante a manutenção do poder. O homem deve. assim, ter para com a Fortuna uma relação de amor, mas não o amor cortês e respeitoso, e sim o amor soldadesco, viril. rude e violento. ${ }^{43}$ que a reduz a um obstáculo ao objetivo pretendido. e que deve ser conquistado. ${ }^{44}$

É curioso notar, nesse ponto, que a associação da fortuna com uma mulher não é fortuita. A mesma violência que é a ela aplicada. poderia sê-lo fosse ela um homem; todavia, a conotação desse uso de violência e da conseqüente submissão seriam totalmente diferentes: para Maquiavel, um varão se submeteria apenas para evitar a dor, mas certamente guardaria rancor e ressentimento, que poderiam levá-lo a

41. "... às vezes me sinto um tanto inclinado a esta opinião; entretanto, já que o nosso livre-arbítio não desapareceu, julgo possivel ser verdade que a fortuna seja árbitro de metade de nossas açôes, mas que lambem deixe ao nosso governo a outra metade, ou quase" (p. 119).

42. "Estou convencido do seguinte: é melhor ser impetuoso do que timido [no original, rexpettivo], porque a fortuna é mulher, é é necessário, para dominá-la, bater-lhe e contrariá-la" (p. 122).

43. DE GRAZIA. Maquiavel..., p. 225.

44. Ibid., p. 226. 
querer vingar-se, donde o príncipe virtuoso deveria tomar medidas para conter esse risco de reação. ${ }^{45}$ Sendo a fortuna uma mulher, o quadro é outro: ela não se deixa vencer porque tema a dor, mas porque gosta de apanhar; destarte, ela não se submete, mas é seduzida pelo homem de virtü. ${ }^{46}$

É essa fortuna que há de ser domada por meio da virtù, através de uma constante antecipação e preparação para variações, inclusive mediante ações ofensivas, pois ela favorece os impulsivos. Esse domínio. contudo nunca será perfeito, e por duas razões. A primeira liga-se a uma limitação mais propriamente humana: a constante preparação para as variações da fortuna exige que o homem, por vezes, altere seu modo de proceder, inclusive quando este está a the trazer sucesso; ocorre que isso é demais para os homens, mesmo os mais prudentes, cuja natureza é de acomodar-se às suas inclinações e aos caminhos bem sucedidos. ${ }^{47}$ A segunda, por outro lado, tem a ver com a impossibilidade de se estar preparado para tudo, com o fato de que, por maior que seja a virtù do príncipe, a fortuna pode, caprichosamente, surpreendê-lo, afinal cabe a ela ainda o governo de metade das ações dos homens. Por ambas as razões, a virtù, cuja característica principal é a capacidade de antecipar e se preparar para as mudanças da fortuna, encontra seu limite na própria fortuna. Nada garante que um príncipe de grande virtù, que tenha lançado sólidas bases para seu estado, que tenha cumprido todas as recomendações contidas n' $O$ Principe. não venha a ser vitimado por um assassino que não se importe em morrer por seu ato. ${ }^{48}$ ou venha a cometer um único erro que o faça ser repreendido pela fortuna com sua ruína. como o fez Cesare Borgia. Para Maquiavel, o mundo, governado em parte por uma mulher volúvel e implacável, não é um lugar seguro nem para homens virtuosos.

45. "Dai se há de observar que os homins devem ou ser mimados ou aniquilados, porque, se $\dot{e}$ verdade que podem vingar-se das ofensas leves, das grandes não o podem; por isso, a ofensa que se fizer a um homein deverá ser de tal ordem que não se téma a vingança" (p. 10).

46. DE GRAZIA. Maquiavel..., p. 226.

47. "Não há homem suficientemente prudente que saiba acomodur-se a isso, ou porque não consegue desviar-se da linha para onde se inclina sua natureza, ou porque, tendo sempre prosperado trilhando um cerlo caminho, não pode admitir qué se deva afastar dele"'(p. 121).

48. [Comentando o assassínio de Antonino Caracalla por um centurião de seu cxército] "Dai se dene ressaltur que mortes como essas, decorrentes du decisão de um espirito obstinado, são inevitáveis aos principes, pois qualquer um que não se importe de morrer poderá atacá-lo; porém, não deve o principe receá-las demais, visto serem rarissimas" (p. 95). 
Conclusão: Uma "moral" de resultados.

Mas, elucidado, ainda que, aqui, de forma apenas esboçada, o significado da virtù maquiaveliana, não se responde a uma pergunta que não é feita no livro, mas que parece ter fundamental importância na solução do enigma de Maquiavel: por que é essencial para um principe ter virtù? Por que é imperativo que príncipe saiba "não ser bom" isto é, que seja capaz de não deixar considerações de cunho moral interferir na tomada de decisões sem as quais não se pode manter o estado? Em outras palavras, o que justifica que o principe tenha uma moral própria, dissociada da moral comum aos cidadãos do principado ${ }^{49}$ Em uma palavra, a resposta de Maquiavel a tal questão subentendida é: necessidade; o príncipe deve assim agir porque é o que precisa fazer.

Nos Discursos sobre a primeira década de Tito Livio, Maquiavel afirma que os homens agem ou por necessidade, ou por escolha, ${ }^{50}$ nesse sentido, coloca-se ao lado de uma longa tradição filosófica que afirma que um ato só pode ser moral se houver escolha. ${ }^{51}$ um bom ato praticado por acaso, sem intenção. não se distingue de um ato imoral praticado por coação. O julgamento ético, assim, somente pode ser feito em relação a atos cuja prática tenha sido resultado de uma livre decisão do agente; quando a prática do ato não envolve deliberação, mas representa tãosomente um efeito de uma causa externa ao querer do agente, o juízo perde o sentido.

Em todos os exemplos de ação política que fornece, Maquiavel deixa bem claro que o príncipe, quando age, o faz movido pela onipresente necessidade de conservar o estado, tanto em face de perigos atuais, quanto contra perigos antecipados. Não se trata de uma questão de escolha ou de exercício de livre arbitrio por parte do príncipe, mas sim de uma ação necessária. Necessária, é bom que se o diga, porque Maquiavel entende que é da natureza do homem buscar poder e

49. “'́ preciso entender que um principe, sobretudo o principe novo. não pode observar todas aquelas coisas pelas quais os hoinens são considerados bons, sendo-the frecrientementu necessávio, para manter o poder. ugir contra a fé, contra a caridade, contra a humanidade e contra a religião" (p. 85).

50. "E perché gli uomini operono o per necessità o per elezione..." (Discursos, I, 1).

51. DE GRA7.IA. Maquiavel..., p. 84-5. 
riqueza, ${ }^{52}$ logo qualquer ameaça ao estado é causa de uma reação do príncipe, como efeito imediato, não entrando em questão seu livre arbítrio.

Se, ao analisarmos as ações dos príncipes, entendermos que estamos diante de uma ação praticada não por escolha, mas por necessidade, fica sem sentido qualquer tentativa de impor limites éticos a tal conduta. A necessidade simplesmente afasta qualquer influência que a moral possa ter na determinação da ação do príncipe, que será feita unicamente por critérios de expediência e utilidade. ${ }^{3}$ Dai que o príncipe. se tiver virtù, saberá "não ser bom", pois deve identificar o que é o necessário fazer na circunstância e executá-lo, sob pena de, deixando de agir em homenagem a preceitos morais, deixar perccer o estado.

O juízo que se pode fazer à ação política, então, é unicamente o juizo dc eficiência, ${ }^{54}$ um príncipe merece ser louvado quando lezz o que devia fazer. ${ }^{55}$ quando, podendo, satisfez sua ambição e quando. não a podendo realizar, refreou seus impulsos, ${ }^{56}$ quando, entretanto, ele deixar de agir em caso de necessidade, ou insistir em ir além do que suas forças the permitem almejar, arruinando seu estado, merece o opróbrio. Esse, ressalte-se, é o erro da formulação da famosa máxima maquiavélica que por sinal não se encontra em lugar nenhum du obra do florentino - que enuncia que "os fins justificum os meios" Não se trata, aqui, de um problema de justificação. mas sim de necessidade. de causalidade: melhor seria, então, dizer que os fins determinam os meios.

52. "É, de fato, muito natural e comum o desejo de conquistar" (p. 14). "Pois se pode ver que os homens, no que diz respeito aos caminhos que conduzem aos fins que perseguem. isto é. glória e riquezas, agem de maneira diversa" (p. 120).

53. "Um príncipe prudente nào pode, nem deve, guardar a palavra dada, quando isso se torna prejudicial ou quando deixem de existir as razões que o haviam levado a prometer. Se os homens fossem todos bons. c'ste preceito não seria bom, mas, como são maus e não mantém sua palarra para contigo, não tens tambèm yue cumprir a sua" (p. 84).

54. "Como não hà tribunal onde reclamar das ações de lodos os homens, e principalmente dos principes, o que conta por fiun são os resultados" (p. 85).

55. "Cesare Borgia era tidu cumo cruel; no entanto, sua crueldade reergueu a Romanha. reunificou-a e restituiu-lhe a paz e a lealdade. o que, bem considerado. uvidenciará que ele foi muito mais piedoso do que o povo florentino. o qual, para evitar a fama de cruel, permitiu a destruição de Pisıóia" (p. 79).

56. " $\dot{E}$, de fato, muito natural é comum o desejo de conquistar. Quando, podendo. os homens o realizam. merecem ser louvados e não criticados; mas, quando não podem e querem realizá-lo de qualquer modo, nestc caso estão errados e devem ser recriminados" (p. 14). 
Maquiavel, todavia, não exclui de todo a possibilidade de julgamento moral. Ele sabe que os homens sempre irão julgar uns os outros com referência a preceitos morais, c mais ainda os príncipes, expostos como estão ao olhar público pela própria dimensão de suas ações. Por isso mesmo sabe que é inevitável que alguns, como ('esare Borgia, venham a ser considerados cruéis, ímpios, desonestos, ou então, como Moisés, Ciro e Teseu, corajosos, inteligentes, justos, magnânimos etc. Só que esse julgamento depende mais do resultado final de sua trajetória do que propriamente dos atos individuais que a compõem. O sucesso faz com que pequenos pecados se esvaeçam. o fracasso amplifica seu impacto: caso tivesse sobrepujado seus inimigos e conseguisse unificar a Itália, certamente o Duque Valentino teria uma fama menos agourenta e sinistra do que a que acompanha sua memória até os dias de hoje. Ou, para trazer à baila um exemplo contemporâneo, caso não houvesse surgido um movimento de resistência tão ousado e eficaz em chantagear governos estrangeiros com imagens de cabeças cortadas, e caso o processo de reconstrução nacional estivesse adiantado, poucas criticas receberia hoje o Presidente dos EUA por sua decisão unilateral de invadir o Iraque. Como esse cenário rosa imaginado por alguns assessores do Pentágono não se verificou na prática, muito pelo contrário, todos os atos tidos como injustificáveis desde a decisão de ir ù guerra ganham uma dimensão ainda mais dramática.

A última pergunta que ora tentaremos responder, derivada dessa anterior, diz respeito a quem aproveita a ação do príncipe. É uma questão complicada, especialmente porque para respondê-la não basta a análise d'O Príncipe: deve-se também considerar o restante da obra de Maquiavel, especialmente os Discursos. mas também sua obra como diplomata, dramaturgo e poeta. além de sua correspondência. Neste trabalho. por questões de tempo e de extensão, limitar-nos-emos a apontar um indício do que consideramos ser a melhor resposta.

Ao analisar os exemplos de príncipes novos que ascenderam ao poder com armas próprias e virtù, Maquiavel deixa escapar que o resultado do sucesso de Moisés, Ciro, Rômulo e Teseu foi a "honra e felicidade de suas pátrias" (p. 25). No outro extremo do livro. na exortação final, lemos que o sucesso de um príncipe novo que conseguisse unificar a Itália seria a sua "glória pessoal e beneficios para todos os homens do país" (p. 123). Maquiavel parece querer dizer que o beneficiário último da virtù de um príncipe é o estado, entendido como a comunidade política. e que é em função dos resultados para com ele que se julgará o succsso ou o fracasso do príncipe. 
Desse ponto de vista, temos que, do ponto de vista da Itália no início do Séc. XVI, era necessário ter um príncipe virtuoso que a unificasse e expulsasse de lá os poderosos estrangeiros que a esfacelaram. Nesse ponto vem à mente o trágico embora se possa dizer justo - destino de messer Remiro de Orco: enquanto fora útil para o fím de pacificação da Romanha, teve poder e prestígio; quando esse objetivo já havia sido alcançado e ele então representava um problema, foi mandado cortar ao meio em praça pública. Aparentemente essa é a mensagem de Maquiavel: um príncipe forte é necessário para unificar e pacificar a Itália, e livrá-la dos bárbaros; uma vez que isso tenha sido conseguido, a existência de um príncipe cujas inclinações pessoais podem conflitar com as necessidades do estado torna-se um risco que já não mais se justifica correr, sendo o caso de substituí-lo por outra forma de governo. E, como o próprio florentino, no início d'O Príncipe, afirma que "todos os estados, todos os domínios que tiveram e têm poder sobre os homens foram e são ou repúblicas ou principados" (p. 3), fica mais claro qual o seu projeto de longo prazo para uma Itália finalmente unificada.

São Paulo, março de 2004. 